\title{
The Wall inside the brain: Overestimation of distances crossing the former Iron Curtain
}

\author{
CLAUS-CHRISTIAN CARBON \\ Freie Universität Berlin, Berlin, Germany \\ and \\ HELMUT LEDER \\ Universität Wien, Vienna, Austria \\ and Freie Universität Berlin, Berlin, Germany
}

\begin{abstract}
A study of distance estimations between German cities investigated the organization of mental maps and their specific deviations from reality. Potential factors for the deviation of mental maps from reality are physical barriers, emotional involvement, and semantic unity. Distance estimations between cities situated in different former parts of Germany (East or West) were systematically overestimated compared to distances of cities located in the same parts of Germany. This trend was strengthened when participants had a negative attitude toward the reunification of Germany. The impact of these results is far reaching, because overestimated distances between both German parts indicate that there still exists a mental gap between East and West_even in young people-15 years after the German reunification.
\end{abstract}

The German reunification in 1990 ended four decades of political separation by the "Iron Curtain" (Churchill, 1974). Here we show that even in young people, this historical past is still represented in their mental maps.

For a long time, it was assumed that "mental maps" (Tolman, Ritchie, \& Kalish, 1992) are like real cartographic maps in the sense that they accurately represent distances and directions between locations in the environment (see Kuipers, 1982; Piaget, Inhelder, \& Szeminska, 1960). However, since the seminal work of Ekman and Bratfisch (1965), this view of mental maps and their isomorphism to graphical maps has been reassessed because research has shown that spatial representations are systematically distorted. Lloyd (1989) identified three different factors that often lead to distortions: processing factors, topographical factors, and person factors. Alignment and rotation errors are typical processing distortions (Tversky, 1981). Tversky argued that humans cannot represent absolute locations, but can represent relative locations. For example, a person asked to describe the relative alignment of Europe and the United States might reply, "Europe is situated east of the U.S." rather than saying "north" or "south." In rotation errors, the natural axes induced by a figure converge with cardinal axes (e.g., horizontal, vertical, tilted by $45^{\circ}$ ). Typical topographic factors include major environmental barriers as

The authors thank three anonymous reviewers for their helpful comments and Melissa Võ for proofreading the text. Correspondence and requests for materials should be addressed to C.-C. Carbon, Freie Universität Berlin, Institute of General, Cognitive, and Biological Psychology, Habelschwerdter Allee 45, D-14169 Berlin, Germany (e-mail: ccc@ experimental-psychology.de). well as the relative density or salience of areas and locations (see Hirtle \& Jonides, 1985; McNamara \& LeSueur, 1989; Rinck, Haehnel, Bower, \& Glowalla, 1997). Furthermore, personal factors, such as the type of activity people undertake in the environment, how familiar people are with the environment, and how emotionally involved people are with the setting (Lloyd, 1989) also affect spatial perception. For instance, Ekman and Bratfisch (1965) identified political and emotional factors for systematic distortions. Cities belonging to different political systems or cities for which participants feel low emotional involvement are usually estimated as being farther away than are cities within the same political system or cities with which participants have a high emotional involvement (Ekman \& Bratfisch, 1965).

\section{The Present Study}

Knowledge about systematic distortions of distance estimations can be used to test interesting hypotheses about the former separation of East and West Germany, known as the "Iron Curtain." Because we are aware that physical or ideological barriers or the presence of different political systems can increase subjective distance judgments, overestimations of distances between cities suggest that these cities are being categorized as belonging to a different superstructure or hierarchy (Hirtle \& Jonides, 1985; McNamara, 1986). According to the logic of Ekman and Bratfisch (1965), systematic overestimations of distances between cities suggest that the viewer has low emotional involvement with the city located as more distant (see, e.g., Lundberg, Bratfisch, \& Ekman, 1972).

Since its reunification in 1990, Germany is organized as a federal republic consisting of 16 federal states. Each state has its own constitution, police force, and sovereign 
rights. Because differences among the states and across borders are significant, we would expect observers to systematically overestimate distances across the borders of federal states (Hirtle \& Jonides, 1985). However, if the former separation of Germany persists in individuals' mental maps, we would expect distances across the former border of East and West Germany to yield even stronger overestimations than distances crossing the borders of the federal states (see Bratfisch, Ekman, Lundberg, \& Kruger, 1971; Lundberg et al., 1972; Stanley, 1971). Thus, the emotional involvement and the feeling of unity among German citizens can reflect psychological "distances" between cities.

In order to exclude simple hierarchic effects of federal state borders, we used only cities from different federal states in the present study. A. Stevens and Coupe (1978), for instance, demonstrated that participants consulted their mental map of the layout of the states of the U.S. and used this knowledge, at least in part, to estimate the relationship between two U.S. cities. Thus, by pairing cities from East Germany with cities from West Germany, we are able to test specific East-West overestimations in relation to simple overestimations across the borders of two federal states within the former West or within the former East.

\section{METHOD}

We were interested in whether participants still hold a mental representation of the former Iron Curtain. Therefore, we asked the participants to evaluate distances between German cities that were within the same former part of Germany or across the former Iron Curtain.

\section{Subjects}

Eighty-three participants ( 54 female; 32 raised in West Germany; overall mean age: 25.9 years) took part in this study. All participants had normal vision or were corrected to normal vision; all were naive to the purpose of the study. They were given 5 Euros or course credit for their participation.

\section{Apparatus and Stimuli}

Eleven German cities ${ }^{1}$ were preselected (five in the West and six in the East, including Berlin, which was in East Germany but was itself divided into East and West sectors). Each of the 11 cities belonged to a different federal state of Germany. The locations of all cities are shown in Figure 1.

\section{Procedure}

The participants first rated their attitudes toward the German reunification. The attitude toward the German reunification was measured on a four-point rating scale from 1 to $4(1=$ very negative; $2=$ negative $; 3=$ neutral $; 4=$ positive .

Then the participants had to estimate air distances between 11 preselected German cities as all 110 possible pairs of cities were presented on a computer screen. Each time, they were instructed to estimate the air distance between two cities (in km) "as a crow flies" (Wender, Wagener-Wender, \& Rothkegel, 1997). This was done by typing a number of kilometers on the screen and then pressing the return key. The order of the trials was randomized by an experimental control software. To control for any unobserved noncommutativity of distances (see Cadwallader, 1979), participants rated both directions of each possible distance. The whole estimation task lasted about $20 \mathrm{~min}$.

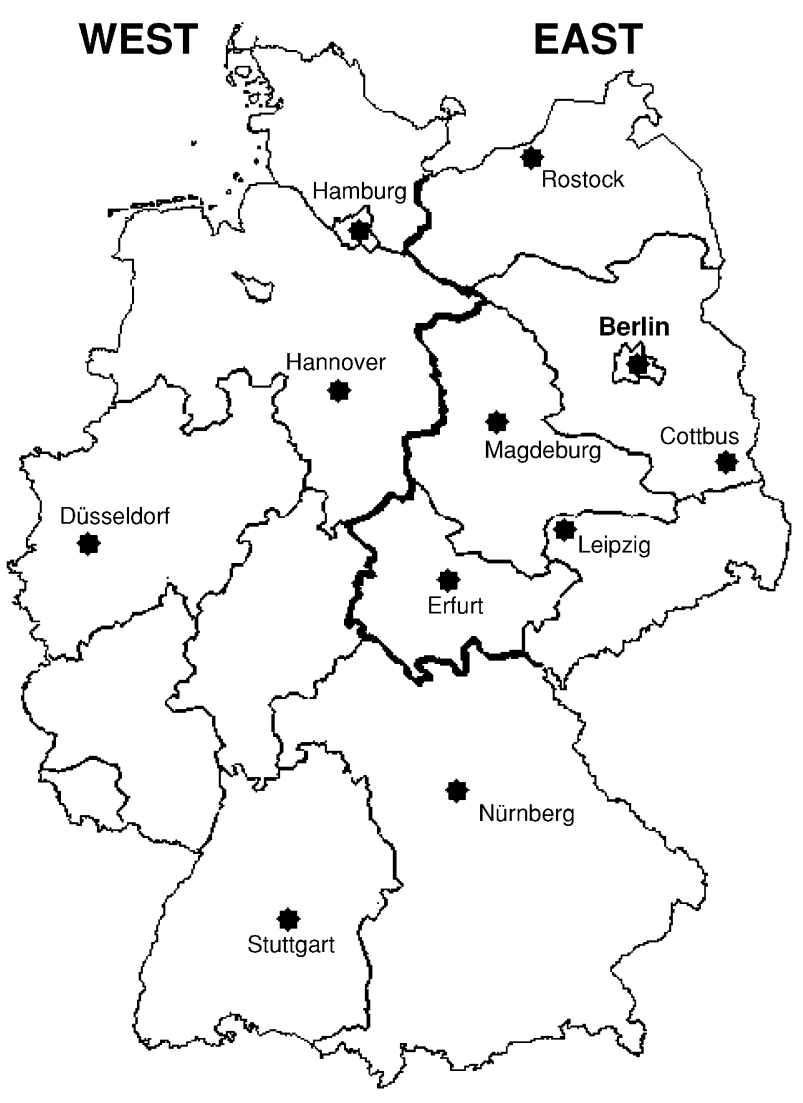

Figure 1. The map of Germany showing the 11 cities used in this study. The borders of the federal states are indicated by thin lines; the border between the former West Germany and the former East Germany is shown by a thick line.

\section{Results}

In the present study, we focused on two major factors. First, we were interested in whether distances across the former Iron Curtain are systematically overestimated compared with distances located entirely within the same former part of Germany. Second, we were interested in whether such an effect depends on the participants' attitude toward the German reunification. We investigated both factors by analyzing the full data set first. In addition, we validated the results by comparing only same distant cities to circumvent distance-dependent effects.

As the distributions of the city distances for the within and the across set were not completely the same, we calculated an index (relative distance) to determine the estimated (psychological) distance related to the real (physical) air distance. Furthermore, because only five participants evaluated their attitude toward the German reunification as "very negative," we joined their data with the data of the group with "negative" attitudes, creating a group shortly termed negative.

For the first analysis, we used the full data set, including the distances with Berlin as one anchor point (Berlin), with a one-way repeated measurement analysis of variance (ANOVA) with the factor distance type (within, 


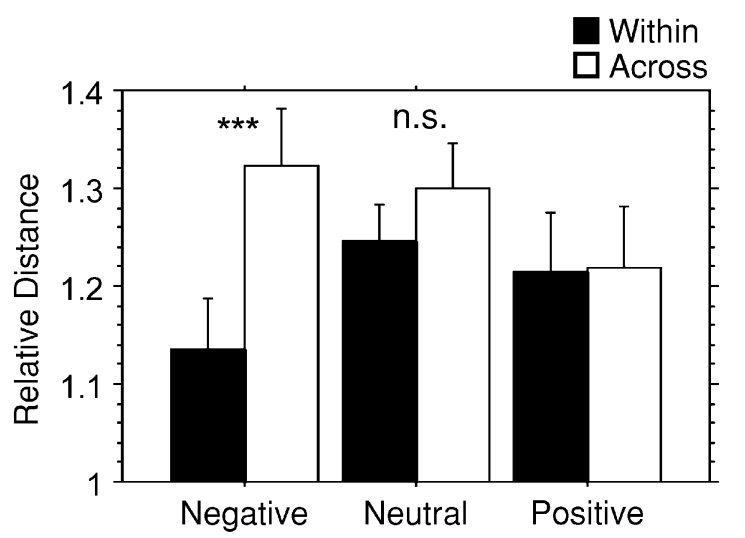

Figure 2. Estimated distances for across and within distances in comparison with real distances for all six selected distance pairs for which the distances were matched. $* * * p<.001$.

across, Berlin). The factor distance type was significant $\left[F(2,164)=4.09, p=.0185, \eta_{p}^{2}=.048\right]$, with a significant difference between within $(M=1.228)$ and across $(M=1.294), p=.0113$, and a trend of significance between across and Berlin $(M=1.233), p=.0184$, n.s., tested by Bonferroni-adjusted post hoc tests. Our data revealed that distances of cities belonging to the different parts (across) of Germany (former GDR: East and former FRG: West) were systematically overestimated compared with distances within the same former part (within). The results of the across-pairs estimates indicate that the former border between East and West is still more salient than the borders between federal states within either the former East or West Germany.

Interestingly, the estimations including Berlin did not differ from within distances, $p>.85$. One reason might be that the study was carried out in Berlin. Therefore, for this study, Berlin was the epicenter because participants' everyday lives were located there. Moreover, because Berlin had a Western and an Eastern part, it belonged to both political systems and is difficult to categorize. Therefore, all distances including Berlin as an anchor point were omitted for the succeeding analyses.

According to the psychophysical law of S. S. Stevens and Galanter (1957), the psychological distance follows a power function of the physical distance with an exponent smaller than 1, which means that longer distances will be relatively underestimated (cf. Lundberg \& Ekman, 1973; McNamara, Ratcliff, \& McKoon, 1984). To circumvent this problem, we ran a cross-check of the above results by using only those distances that were nearly the same in size for the across and within conditions (differing at a maximum of $9 \mathrm{~km}$ ). Overall, there were six distances that achieved this criterion. ${ }^{2} \mathrm{~A}$ onetailed $t$ test once again demonstrated a significant overestimation of across versus within pairs $[t(82)=5.30, p<$ $.001]$. An analysis based on the item level revealed that 5 of 6 across distances were following this overall trend and were estimated longer than their within counterparts (see
Figure 2). Only the distance Hamburg-Rostock deviated from this pattern of results-probably due to the close historic relationship of both cities (the Hanseatic League).

Moreover, we investigated modulating effects of the attitude toward the German reunification and the distance estimations of within and across distances (again for the full data set, excluding distances with Berlin). Therefore, a two-way, mixed-design ANOVA with the between-subjects factor attitude (negative, neutral, positive) and the withinsubjects factor distance type (within vs. across) was used. The main factor distance type $[F(1,80)=12.17, p<.001$, $\left.\eta_{p}^{2}=.132\right]$, and the interaction between distance type and attitude $\left[F(2,80)=4.80, p=.0107, \eta_{p}^{2}=.107\right]$, were significant.

In order to illustrate the dissociative influence of attitude on the across and within distances, we further analyzed the data by testing the differences between across and within for each level of attitude by three independent one-tailed $t$ tests. There was a significant difference between both distance types for the group with negative attitudes toward the German reunification $[t(21)=3.71$, $p<.001]$, and a strong trend for the neutral attitude group $[t(39)=1.68, p=.0505$, n.s. $]$, but not for the positive attitude group $[t(20)<1$, n.s.] (see Figure 3 ).

Furthermore, we analyzed the relation of estimated to real distances for both distance types with regression analyses (see Figure 4). The data for across and within distances separated most obviously for the negative attitude group. Both curves fitted very well to a power function $\left(R^{2} \mathrm{~s}>.97\right)$ with an exponent smaller than 1 . This was also the case for all other conditions $\left(R^{2} \mathrm{~s}>.84\right)$, which validates the nature of the psychophysical law assumed by S. S. Stevens and Galanter (1957) once again.

\section{DISCUSSION}

This study demonstrated systematic overestimations of distances between German cities that are situated across

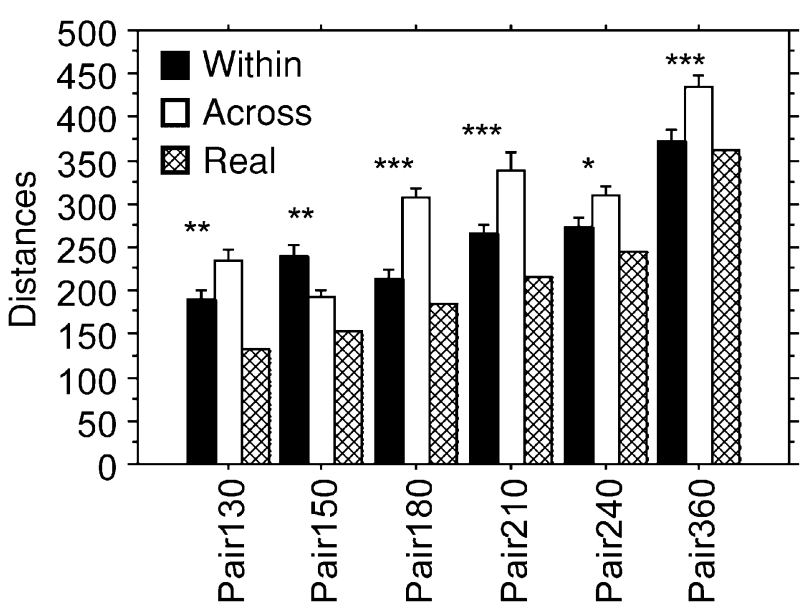

Figure 3. Relative distance estimations for across and within distances dependent on attitudes toward the German reunification. $* p<.05 . \quad * * p<.01 . \quad * * * p<.001$. 

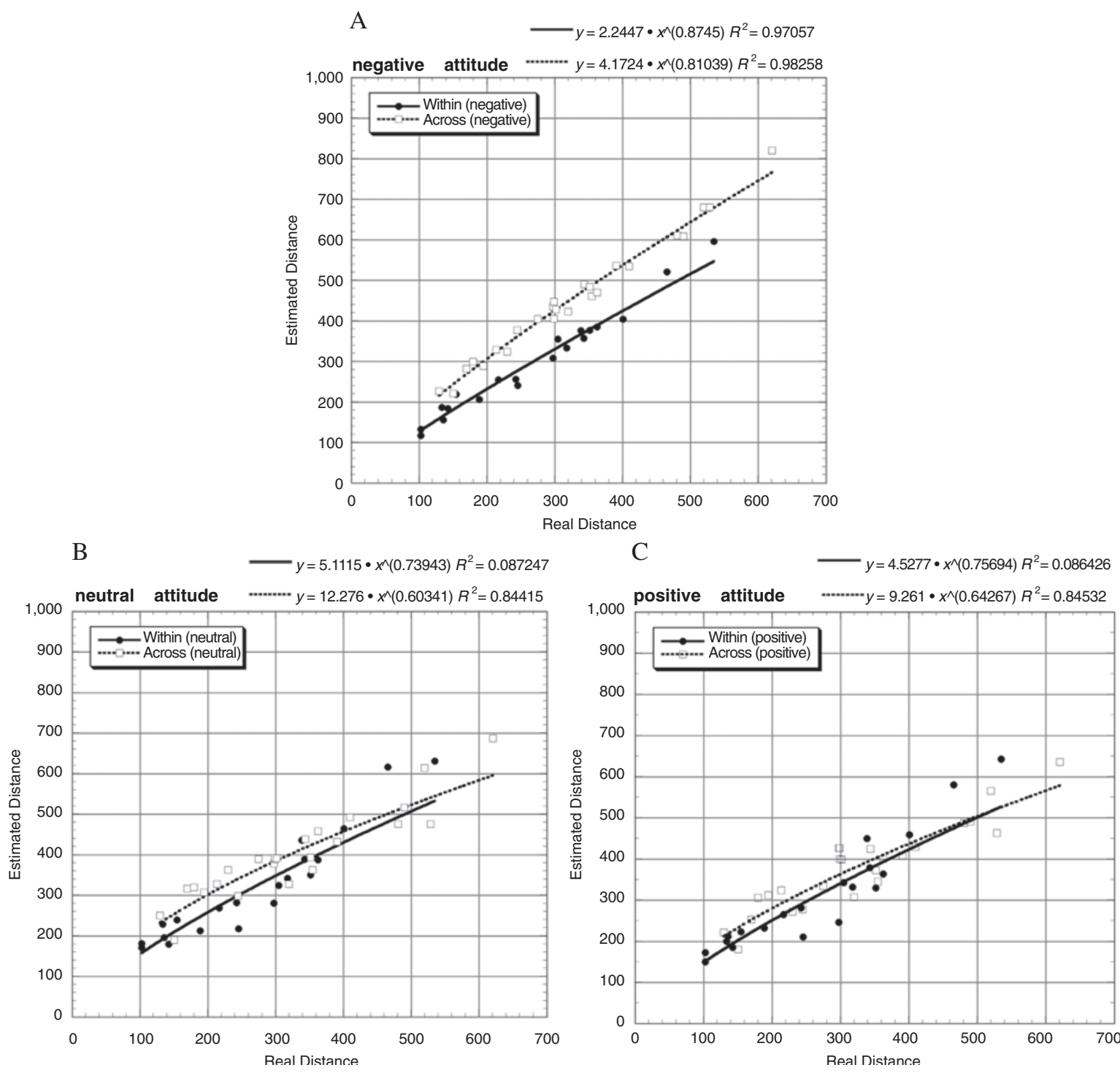

Figure 4. Scatterplots of estimated and real distances (in kilometers) for participants with (A) negative attitude, (B) neutral attitude, and $(C)$ positive attitude toward the German reunification. Solid dots show data for within distances; rectangles show data for across distances.

the former Iron Curtain, especially when the participants had a negative attitude toward the German reunification.

One explanation for the overestimates across distances would be that the two former political systems are still represented in the participants' mental maps (see Beck \& Wood, 1976; Ekman \& Bratfisch, 1965). An alternative explanation would be that German cities located in the West belong to a different hierarchical system than did cities in the East (Hirtle \& Jonides, 1985; McNamara, 1986). Both interpretations suggest that the differentiation between the former East and the former West part of Germany is more pronounced than the differentiation across different federal states within either former German part, even though Germany is organized as an equitable group of 16 federal states.

Furthermore, it does not seem valid to interpret these characteristic overestimations on the basis of the findings of A. Stevens and Coupe (1978), who suggested that participants' distance estimations were abstracted from the exact position biased by the general superposition of the states to which they belonged. In the case of East and West Germany, the general heuristic would be that "East is eastern of West," which is valid for all across pairs of cities used in this study with the exception of across pairs containing Nürnberg/Nuremberg. As all other West German cities of the across pairs are indeed situated to the west of 
the corresponding East German cities, such a simple hierarchic heuristic would lead to relatively accurate estimations, but would not be capable of systematic overestimations. Therefore, the specific design used here precludes the explanation by such an artifact.

A negative attitude toward the German reunification was an important factor for the overestimation. The more negative the attitude was, the more different were estimations of across and within distances. For participants whose attitude toward the German reunification was negative, there was a kind of "mental wall" between both former political German states. The results are quite discouraging when interpreted as an indicator of the success of the mental unification of both German states. The political past seems still cognitively representedeven in young people who have lived all their adult lives in a different historical situation.

\section{REFERENCES}

BECK, R. J., \& Wood, D. (1976). Cognitive transformation of information from urban geographic fields to mental maps. Environment \& Behavior, 8, 199-238.

BratFisch, O., Ekman, G., Lundberg, U., \& Kruger, K. (1971). Subjective temporal distance and emotional involvement. Scandinavian Journal of Psychology, 12, 147-160.

CADWALlaDER, M. (1979). Problems in cognitive distance: Implications for cognitive mapping. Environment \& Behavior, 11, 559-576.

Churchill, W. (1974). The sinews of peace. In R. R. James (Ed.), Winston Churchill: His complete speeches 1897-1963 (Vol. VI, 19431949). New York: Chelsea House.

Ekman, G., \& BRATFISCH, O. (1965). Subjective distance and emotional involvement. A psychological mechanism. Acta Psychologica, 24, 430-437.

HiRTLE, S. C., \& Jonides, J. (1985). Evidence of hierarchies in cognitive maps. Memory \& Cognition, 13, 208-217.

Kuipers, B. (1982). The "map in the head" metaphor. Environment \& Behavior, 14, 202-220.

LLOYD, R. E. (1989). Cognitive maps: Encoding and decoding information. Annals of the Association of American Geographers, 79, 101-124.

LundberG, U., Bratfisch, O., \& Ekman, G. (1972). Emotional involvement and subjective distance: A summary of investigations. Journal of Social Psychology, 87, 169-177.
Lundberg, U., \& Ekman, G. (1973). Subjective geographic distance: A multidimensional comparison. Psychometrika, 38, 113-122.

McNamara, T. P. (1986). Mental representations of spatial relations. Cognitive Psychology, 18, 87-121.

MCNamara, T. P., \& LeSueur, L. L. (1989). Mental representations of spatial and nonspatial relations. Quarterly Journal of Experimental Psychology: Human Experimental Psychology, 41, 215-233.

McNamara, T. P., Ratcliff, R., \& McKoon, G. (1984). The mental representation of knowledge acquired from maps. Journal of Experimental Psychology: Learning, Memory, \& Cognition, 10, 723-732.

PiAget, J., InHelder, B., \& SzeminsKa, A. (1960). The child's conception of geometry. London: Routledge.

Rinck, M., Haehnel, A., Bower, G. H., \& Glowalla, U. (1997). The metrics of spatial situation models. Journal of Experimental Psychology: Learning, Memory, \& Cognition, 23, 622-637.

StANLEY, G. (1971). Emotional involvement and subjective distance. Journal of Social Psychology, 84, 309-310.

Stevens, A., \& Coupe, P. (1978). Distortions in judged spatial relations. Cognitive Psychology, 10, 422-437.

Stevens, S. S., \& Galanter, E. H. (1957). Ratio scales and category scales for a dozen perceptual continua. Journal of Experimental Psychology, 54, 377-411.

Tolman, E. C., Ritchie, B. F., \& Kalish, D. (1992). Studies in spatial learning: I. Orientation and the short-cut. Journal of Experimental Psychology: General, 121, 429-434.

TVERSKY, B. (1981). Distortions in memory for maps. Cognitive Psychology, 13, 407-433.

Wender, K. F., WAGener-Wender, M., \& Rothkegel, R. (1997). Measures of spatial memory and routes of learning. Psychological Research/Psychologische Forschung, 59, 269-278.

\section{NOTES}

1. East German cities included Erfurt (Thuringia), Leipzig (Saxony), Cottbus (Brandenburg), Rostock (Mecklenburg-Western Pomerania), and Magdeburg (Saxony-Anhalt). West German cities included Hamburg (Hamburg), Nürnberg (Bavaria), Hannover (Lower Saxony), Düsseldorf (North Rhine-Westfalia), and Stuttgart (Baden-Wurttemberg). 2. Pair130: Hannover-Magdeburg $(130 \mathrm{~km})$ and Erfurt-Magdeburg $(136 \mathrm{~km})$, Pair150: Hamburg-Rostock $(151 \mathrm{~km})$ and Stuttgart-Nürnberg $(155 \mathrm{~km})$, Pair180: Erfurt-Hannover $(180 \mathrm{~km})$ and Cottbus-Magdeburg (189 km), Pair210: Hannover-Leipzig (214 km) and Magdeburg-Rostock (217 km), Pair240: Düsseldorf-Hannover (243 km) and Hannover-Rostock (245 km), Pair360: Leipzig-Stuttgart (363 km) and Düsseldorf-Nürnberg $(363 \mathrm{~km})$.

(Manuscript submitted April 29, 2004; revision accepted for publication December 9, 2004.) 